INTEGRITAS : Jurnal Pengabdian

Vol 4, No 2, Desember 2020

ISSN 2580 - 7978 (cetak) ISSN 2615 - 0794 (online)

\title{
PELATIHAN MODEL PEMBELAJARAN SEJARAH BERBASIS RISET DI SMAN 1 YOGYAKARTA
}

\section{RESEARCH TRAINING MODEL FOR HISTORY-BASED RESEARCH IN SMAN 1 YOGYAKARTA}

\author{
Bayu Ananto Wibowo \\ Universitas PGRI Yogyakarta \\ Email: bayuananta@upy.ac.id
}

\begin{abstract}
Abstrak: Pada kegiatan pembelajaran sejarah peserta didik dituntut untuk berfikir kritis, oleh karena itu dibutuhkan sebuah strategi-strategi pembelajaran, metode-metode, ataupun pendekatan pembelajaran, dengan harapan dapat membantu siswa dalam belajar, kreatif, serta merangsang siswa untuk berfikir kritis.Salah satu model yang dapat diaplikasikan adalah model pembelajaran sejarah berbasis riset. Model pembelajaran ini merupakan salah satu metode student-centered learning (SCL) yang mengintegrasikan riset di dalam proses pembelajaran sejarah. Model yang bersifat multifaset ini mengacu kepada berbagai macam metode pembelajaran.Model pembelajaran dapat dan perlu diterapkan oleh guru-guru sejarah di SMAN 1 Yogyakarta, karena model ini dapat memberi kesempatan kepada peserta didik SMAN 1 Yogyakarta untuk mencari informasi, menyusun hipotesis, mengumpulkan data, menganalisis data, dan membuat kesimpulan atas data yang sudah tersusun. Keunggulan tersebut dapat mendorongpeserta didik untuk meningkatkan kemampuan dalam berpikir kritis sekaligus meningkatkan kesadaran sejarah dalam kehidupan sehari-hari.
\end{abstract}

Kata Kunci: Pelatihan Pembelajaran, Model, Riset Sejarah

Abstract: The students are obliged to think critically during the learning activities in history lessons. Therefore, the learning strategies, methods and approaches are need in order to help them to learn creatively and to stimulate them to think critically. One of the models is student-centred learning (SCL) methods which integrates in the learning process. This model is multifaceted because it refers to a variety of learning methods. This model can also be applied by the history teachers at SMAN 1 Yogyakarta because this model gives an arena to the students of SMAN 1 Yogyakarta to look for information, formulate hypotheses, gather the data, analyse the data and write a conclusion based on the data gathered. The benefit to do so is to improve the students' critical thinking skill while rising the awareness of the history teachers at SMA N 1 Yogyakarta.

Keywords: Learning Training, Model, History Research 
INTEGRITAS : Jurnal Pengabdian

Vol 4, No 2, Desember 2020

ISSN 2580 - 7978 (cetak) ISSN 2615 - 0794 (online)

\section{PENDAHULUAN}

Pada kegiatan pembelajaran sejarah peserta didik dituntut untuk berfikir kritis, oleh karena itu dibutuhkan sebuah strategi-strategi pembelajaran, metodemetode, ataupun pendekatan pembelajaran yang dapat dikemas menjadi model pembelajaran dengan harapan dapat membantu siswa dalam belajar, kreatif, dan merangsang siswa untuk berfikir kritis. Seperti yang diungkapkan oleh Sardiman (2015) bahwa melalui pembelajaran Sejarah diharapkan para peserta didik mampu mengembangkan kecerdasan sejarah melalui pola berpikir kritis, kreatif dan imajinatif. Dengan kecerdasan sejarah itu seseorang dapat memahami setiap fenomena dan peristiwa sosio kebangsaan secara cermat, jernih dan komprehensif sehingga melahirkan sebuah kearifan dan kedasaran sejarah.

Untuk memaksimalkan pembelajaran sejarah, maka dibutuhkan model, strategi, metode, atau pendekatan pembelajaran yang dapat menjadi rujukan guruguru sejarah agar lebih maksimal dalam kegiatan pembelajaran sejarah.Salah satu upaya inovasi untuk memaksimalkan kegiatan pembelajaran sejarah adalah dengan menerapkan pembelajaran berbasis riset. Menurut Achmadi (2010) Pembelajaran berbasis riset (PBR) merupakan salah satu metode student centered learning (SCL) yang mengintegrasikan riset di dalam proses pembelajaran. PBR bersifat multifaset yang mengacu kepada berbagai macam metode pembelajaran. Hal ini dipertegas oleh Diah (2010) yang mengungkapkan bahwa pembelajaran berbasis riset (PBR) adalah sebuah metode pembelajaran yang menggunakan authentic learning, problem-solving, cooperative learning, contextual (hands on \& minds on, dan inquiry discovery approach yang dipandu oleh filosofi konstruktivisme.

Penerapan pembelajaran berbasis riset pada kegiatan pembelajaran sejarah di sekolah secara tidak langsung akan mengasah kemampuan peserta didik secara afektif maupun kognitif. Melalui tugas-tugas penelitian sejarah, peserta didik dipacu untuk melakukan proses penelitian sejarah yang terdiri dari Heuristik, verifikasi, interpretasi, dan historiografi. Sumber-sumber masa lampau digunakan secara kritis analitis dan sistematis kemudian disajikan secara tertulis. Sehingga penggunaan model pembelajaran sejarah berbasis riset ini dapat merubah kondisi 
INTEGRITAS : Jurnal Pengabdian

Vol 4, No 2, Desember 2020

ISSN $2580-7978$ (cetak) ISSN 2615 - 0794 (online)

belajar yang pasif menjadi aktif dan kreatif. Mengubah pembelajaran dariteacher oriented ke student oriented. Mengubah modus Ekspositori siswa hanya menerima informasi secara keseluruhan dari guru ke modus Discovery siswa menemukan informasi sendiri.

Berdasarkan alasan tersebut, pengabdi melakukan program pengabdian untuk meningkatkan untuk meningkatkan pemahaman serta kesadaran guru-guru sejarah di SMAN 1 Yogyakarta bahwa model pembelajaran ini mampu meningkatkan kemampuan berpikir kritis peserta didik sekaligus meningkatkan kesadaran sejarah.

\section{METODE PELATIHAN}

Dalam pelaksanaan kegiatan ini, metode pelatihan yang digunakan untuk menyelesaikan masalah adalah penyuluhan yang bertujuan untuk meningkatkan pemahaman serta kesadaran guru-guru sejarah di SMAN 1 Yogyakarta mengenai Model pembelajaran sejarah berbasis riset.Pelatihan inidilaksanakan selama 3 kali pertemuan.Secara rinci pelaksanaan pelatihan dapat jelaskan dalam tabel 1.berikut:

1) Pertemuan pertama, 14 Januari 2020

\begin{tabular}{|c|l|c|}
\hline Sesi ke- & \multicolumn{1}{|c|}{ Kegiatan } & Waktu \\
\hline I & Pembukaan & 15 menit \\
\hline II & $\begin{array}{l}\text { Penyampaian materi pengertian model, strategi, } \\
\text { pendekatan, dan metode pembelajaran }\end{array}$ & 30 menit \\
\hline III & Tanya jawab & 20 menit \\
\hline IV & Diskusi pembelajaran yang sudah diterapkan & 15 menit \\
\hline V & $\begin{array}{l}\text { Diskusikarakteristik dan kesulitan siswa saat } \\
\text { belajar sejarah }\end{array}$ & 10 menit \\
\hline VI & Evaluasi dan Penutup & 10 menit \\
\hline
\end{tabular}


INTEGRITAS : Jurnal Pengabdian

Vol 4, No 2, Desember 2020

ISSN 2580 - 7978 (cetak) ISSN 2615 - 0794 (online)

2) Pertemuan Kedua, 20 Januari 2020

\begin{tabular}{|c|l|c|}
\hline Sesi ke- & \multicolumn{1}{|c|}{ Kegiatan } & Waktu \\
\hline I & Pembukaan & 15 menit \\
\hline II & $\begin{array}{l}\text { Penyampaian materi model pembelajaran sejarah } \\
\text { berbasis riset }\end{array}$ & 30 menit \\
\hline III & $\begin{array}{l}\text { Penyampaian materi metode, model, pendekatan } \\
\text { dan strategi pembelajaran sejarah }\end{array}$ & 30 menit \\
\hline IV & Tanya jawab & 15 menit \\
\hline V & $\begin{array}{l}\text { Diskusi rencana pertemuan ketiga (guru sejarah } \\
\text { diarahkan agar mengumpulkan data prestasi } \\
\text { peserta didik untuk diolah) }\end{array}$ & 15 menit \\
\hline VI & Evaluasi dan Penutup & 10 menit \\
\hline
\end{tabular}

3) Pertemuan ketiga, 23 Januari 2020

\begin{tabular}{|c|l|c|}
\hline Sesi ke- & \multicolumn{1}{|c|}{ Kegiatan } & Waktu \\
\hline I & Pembukaan & 10 menit \\
\hline II & Penyampaian materi pengolahan data survei & 30 menit \\
\hline III & $\begin{array}{l}\text { Penyampaian materi penelitian survei sebagai } \\
\text { hasil penerapan model pembelajaran sejarah } \\
\text { berbasis riset }\end{array}$ & 30 menit \\
\hline IV & Tanya jawab & 15 menit \\
\hline V & Diskusi pengolahan data SPSS & 15 menit \\
\hline VI & Evaluasi dan Penutup & 10 menit \\
\hline
\end{tabular}

\section{HASIL DAN PEMBAHASAN}

Pelaksanaan program pengabdian yang telah dilakukan oleh pengabdi selama tiga kali pertemuan mendapatkan apresiasi yang positif dari guru sejarah. Guru sejarah merasa mendapatkan peningkatan wawasan baru yang bermanfaat untuk perbaikan pembelajaran sejarah di kemudian hari. Apresiasi tersebut telah tampak selama proses pelaksanaan pengabdian, guru-guru sejarah tampak antusias menghadiri kegiatan pelatihan. 


\section{INTEGRITAS : Jurnal Pengabdian}

Vol 4, No 2, Desember 2020

ISSN 2580 - 7978 (cetak) ISSN 2615 - 0794 (online)

\section{Pertemuan Pertama}

Pada pertemuan pertama, materi mengenai pengertian model belajar dan perbedaannya dengan strategi, pendekatan, metode, maupun tekhnik belajar. Ini sangat bermanfaat karena guru-guru masih kesulitan dalam membedakan apa itu model pembelajaran, apa itu strategi, dan lain sebagainya. Terlihat dari antusias pertanyaan yang mengarah pada pemateri harus dengan contoh kegiatan pembelajarannya. Hal ini penting agar para peserta lebih mudah untuk memahami.

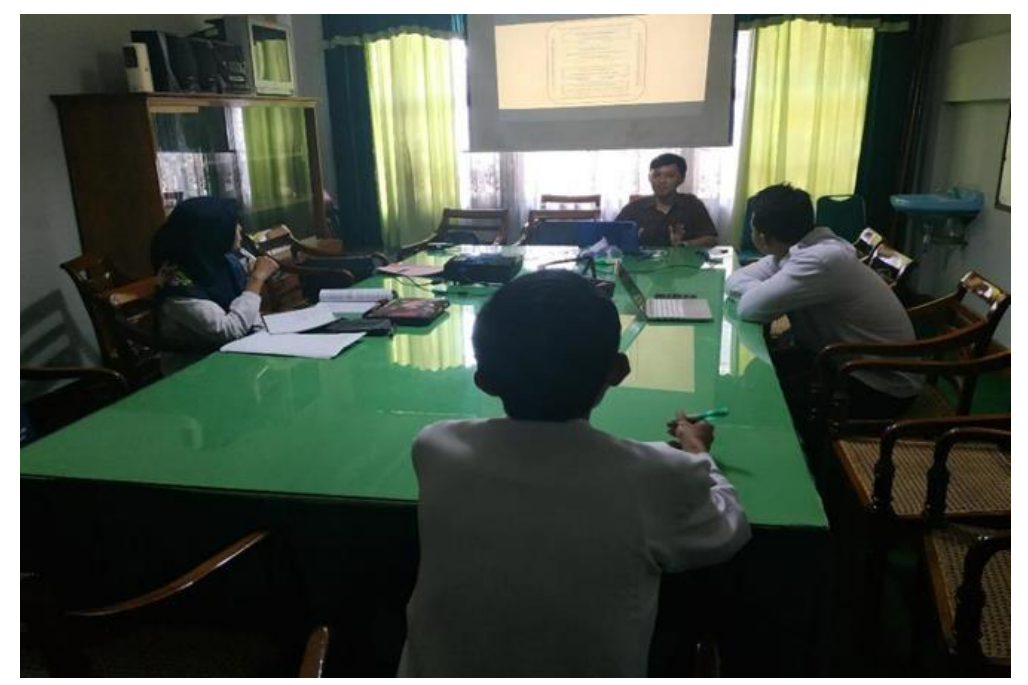

Gambar 1. Pemaparan materi perbedaan model, strategi, pendekatan, dan metode dan penerapannya pada pembelajaran Sejarah (Pertemuan Pertama)

\section{Pertemuan Kedua}

Pada pertemuan kedua, materi yang disampaikan adalah tentang model pembelajaran sejarah berbasis riset. Model pembelajaran ini adalah pengembangan dari model pembelajaran berbasis riset yang diterapkan pada pembelajaran sejarah. Seperti yang kita ketahui sendiri, bahwa sejarah memiliki metodologi penelitian sendiri, yakni Metodologi Penelitian Sejarah. Dalam pelaksanaannya, guru-guru diminta untuk mengenalkan metodologi sejarah terlebih dahulu kepada peserta didiknya. Setelah itu, guru diminta untuk memberikan tugas penelitian sejarah kepada peserta didiknya dengan proses dan metodologi sejarah. Hasil dari penelitian peserta didik tersebut dapat dipertanggung jawabkan melalui laporan dan presentasi. Atau juga guru dapat mengemasnya menjadi sebuah produk buku hasil karya peserta didiknya. 


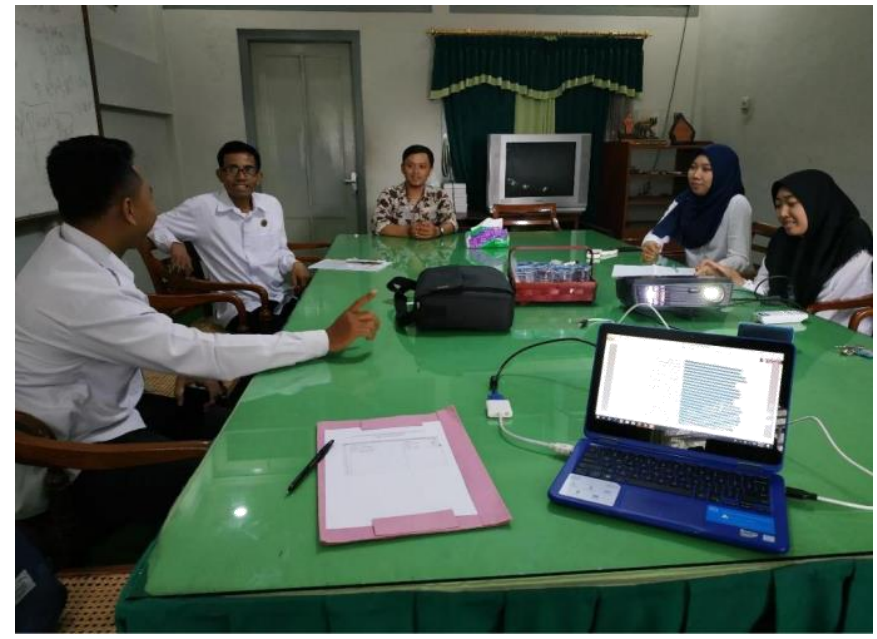

Gambar 2. Diskusi Tentang Model Pembelajaran Sejarah Berbasis Riset (Pertemuan Kedua)

\section{Pertemuan Ketiga}

Pada pertemuan ketiga, materi yang disampaikan adalah pengolahan data penelitian. Materi ini dikhususkan untuk mengetahui keefektifan model pembelajaran sejarah berbasis riset apabila ditinjau dari hasil belajar peserta didiknya setelah menggunakan model tersebut. Guru-guru sejarah juga terlihat fokus dan aktif selama mengikuti jalannya pelatihan pengolahan data penelitian untuk pembelajaran sejarah. Tanya jawab dan diskusi selalu ada setelah pemaparan materi dari pengabdi. Pengalaman guru-guru sejarah dalam mengajar sangat membantu guru-guru sejarah dalam memahami materi yang disampaikan oleh pengabdi sehingga pengabdi mudah menyampaikan materi model pembelajaran sejarah berbasis riset di SMAN 1 Yogyakarta. 


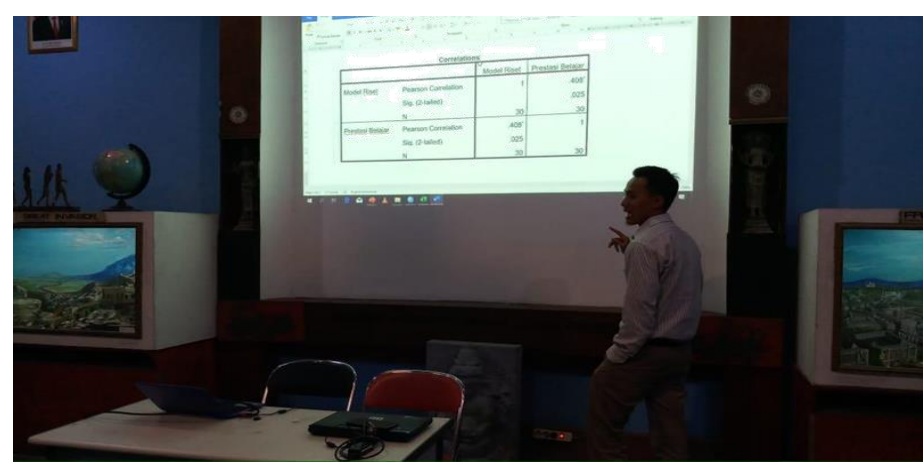

Gambar 3. Diskusi Tentang Pengolahan Data Penelitian yang dilakukan oleh anggota pengabdi (Pertemuan Ketiga)

Guru-guru sejarah menyadari perlu untuk melaksanakan pembelajaran menggunakan model pembelajaran berbasis riset ini dalam pembelajaran sejarah ke depannya, untuk melatih kreatifitas, inovasi, dan kemampuan berfikir kritis peserta didik. Guru-guru sejarah juga menyadari bahwa model pembelajaran sejarah berbasis riset dirasa efektif untuk meningkatkan keilmuan peserta didik. Melalui riset sejarah, peserta didik akan terlatih untuk berpikir kritis, kreatif, dan inovatif dalam kegiatan pembelajarannya. Selama ini guru sejarah hanya berasumsi mengenai prestasi yang dihasilkan dari penerapan metode yang telah diterapkan. Berdasarkan pengamatan pengabdi selama proses pengabdian, guruguru sejarah tampak antusias dan aktif bertanya dan diskusi. Proses tersebut mengidikasikan bahwa guru-guru sejarah SMAN 1 memiliki semangat untuk melaksanakan pembelajaran sejarah berbasis riset dalam pembelajaran sejarah di waktu selanjutnya.

\section{KESIMPULAN}

Kesimpulan dari kegiatan pelatihan model pembelajaran sejarah berbasis riset ini antara lain:

1. Guru-guru sejarah SMAN 1 Yogyakarta cukup memahami pelaksanaan model pembelajaran sejarah berbasis riset.

2. Guru-guru sejarah SMAN 1 Yogyakarta dapat melaksanakan model pembelajaran sejarah berbasis riset dalam pembelajaran sejarah untuk perbaikan masa selanjutnya. 
INTEGRITAS : Jurnal Pengabdian

Vol 4, No 2, Desember 2020

ISSN 2580 - 7978 (cetak) ISSN 2615 - 0794 (online)

\section{UCAPANTERIMA KASIH}

Ucapan terima kasih kami sampaikan kepada:

1. Drs. Miftakodin, MM. selaku Kepala Sekolah SMAN 1 Yogyakarta yang telah mengijinkan pengabdi untuk melakukan pengabdian pada guru-guru sejarah di SMAN 1 Yogyakarta.

2. Guru-guru sejarah SMAN 1 Yogyakarta yang telah bersedia untuk mengikuti kegiatan ini.

3. Drs. Siswanta M.Pd selaku Kaprodi Pendidikan Sejarah Universitas PGRI Yogyakarta.

4. LPPM Universitas PGRI Yogyakarta.

5. Serta pihak-pihak yang paling berkontribusi dalam pelaksanaan kegiatan ini.

\section{DAFTAR PUSTAKA}

Abdurahman, D. (2007). Metode Penelitian Sejarah. Jakarta: Logos Wacana Ilmu.

Achmadi, dkk. 2010. Buku Panduan Pelaksanaan Student Centered Learning dan Student Teacher Aesthetic Role Sharing (STAR). Pusat Pengembangan Pendidikan Universitas Gajah Mada.

Diah, dkk. Pedoman Umum Pembelajaran Berbasis Riset. UGM: 2010

Sardiman. 2015. Menakar Posisi Sejarah Indonesia pada Kurikulum 2013. Jurnal Pendidikan Sejarah, Fakultas Ilmu Sosial, UNY)Volume 11 No 1September 2015)

Sigit. 2013. Pembelajaran Berbasis Riset. Jakarta : Akademia Permata 